other Dutch port, even including Rotterdam; and the "extraordinary idea" of putting a toll on boat and cargo for the upkeep and improvement of the waterway is as old as the Roman Empire, and was the actual regime on the Rhine in the most prosperous days of its commerce-under the French.

I entirely agree with what Dr. Geyl says about the canal dimensions and their origin, but it does not touch my really serious and deliberate assertion that Belgium has suffered, and is suffering, from gross " international servitude."

University College, London.

\section{The Colours of Racehorses.}

IN my "Origin and Influence of the Thoroughbred Horse" (I905, pp. 44I ff.) I supported my other arguments to prove that the "blood" horse orisinated in Libya (North-West Africa), and that his primal colour was bay, by giving in one table the results of my examination of the colours of the winners of the Derby, the Oaks, and the St. Leger: and in another table the colours of the first three horses in each of these races in the three decades from i870-99. Grey does not appear in them at all, and black only twice, whilst chestnut--which (like brown, black, and grey) I maintain is not an original colour, but due to crossing the bay Libyan hor'ses and the ancient dun horses of the Upper European-Asiatic area-shows a steady decrease.

In view of the discussion aroused by the winning of the Derby by a grey (Tagalie) in 1912, and by a black (Grand Parade) in the present year, it may interest some of your readers if I give my tables brought up to date for the last fifty years :- -

\section{TABLE I.-Winners.}

$\begin{array}{lllllllll} & & \text { b. } & \text { b. or br. } & \text { br. } & \text { ch. } & \text { br. or bl. } & \text { bl. } & \text { gr. } \\ \text { I } 870-79 & \ldots & \text { I5 } & \text { o } & 2 & \text { I2 } & \text { I } & \text { I } & \text { o } \\ \text { I } 880-89 & \ldots & \text { I6 } & \text { o } & 5 & 8 & 0 & \text { I } & \text { o } \\ \text { I } 890-99 & \ldots & \text { I7 } & \text { o } & 7 & 6 & 0 & \text { o } & \text { o } \\ \text { I900-09 } & \ldots & \text { I5 } & 4 & 6 & 5 & 0 & \text { o } & \text { o } \\ \text { I9I0-19 } & \ldots & \text { I } 8 & \text { o } & 5 & 5 & \text { o } & \text { I } & \text { I }\end{array}$

'TABLE II.-First Three Horses.

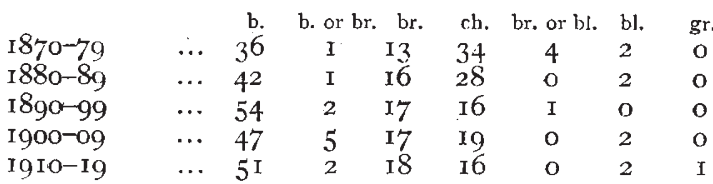

It will be seen that in the first three decades chestnut gave way steadily to bay and brown; that in the fourth decade chestnut dropped $I$ in the winners, but regained a little in the lower horses (I9 against 16 ); that in the present decade, whilst ic retains the same number of winners as in the last, $i_{i}$ has lost the slight gain made in the lower horses; and that in the fourth decade bay dropped in the winners from I7 to $1_{5}$, and in the total from 54 to 47 , but the loss in the winners is more apparent than real, since four bayor-browns were amongst the winners. In the present decade, in spite of the reappearance of black and grey amongst the winners, bay has more winners (18) than ever before, though in the total number of horses it has not quite regained its old position (54).

Thus, in defiance of the sporadic reappearance of black and grey, bay seems steadily bent on superseding all other colours.

Flendyshe, Fen Ditton, Cambridge, William Ridgeway.

$$
\text { November } 4 \text {. }
$$

NO. $26 \mathrm{I}_{3}$, VOL. IO 4 ]

\section{Gravitation and Light.}

IT may or may not have been noticed that the refractivity $(\mu-I)$ at any point, required to produce the Einstein deflection, is the squared ratio of the velocity of free fall from infinity to the velocity of light.

Mariemont, Edgbaston, November 24.

Oliver Lodge.

\section{Variation of Refractive Indices.}

Mr. Twyman (Nature, November 20, p. 3I5) will find in Trans. Chemical Society (I906, vol. Lxxxix., p. 4I7) an account of some observations by Miss Florence Isaac and myself which indicate that the refractive index of a solution of sodium nitrate at the surface of contact with glass is slightly greater than that of the same solution in contact with calcite.

It was our intention to continue and extend these observations, but we have never been able to do so.

The University, Manchester, November 22.

\section{Neon.}

IN response to inquiries, may I use your columns to make two announcements in reference to the above?

First, by making use of a new and more powerful method of positive-ray analysis (the description of which is now in the press), I have succeeded in obtaining measurements of mass and other evidence of sufficient accuracy to prove beyond all dispute that atmospheric neon (atomic weight $20 \cdot 200, \mathrm{O}=\mathrm{r} 6$ ) is a mixture of two isotopes of atomic weights 20.00 and $22 \cdot$ oo correct to about I/Ioth per cent.

Secondly, permission to publish being now granted, a full account of recent experiments on "Neon Lamps for Stroboscopic Work" will shertly appear in the Proceedings of the Cambridge Philosophical Society.

Cavendish Laboratory, Cambridge, F. W. Aston. November I9.

\section{Bird Migration.}

THE captain of the Portuguese steamer Bolama, recently touching here on her voyage from Cape Verde Islands to Lisbon, reports that near the Canary Island, Las Palmas, his ship was visited by an immense cloud of swallows settling in thousands upon every part of the vessel and resting until early dawn, when almost every bird departed. Nothing is known as to the direction in which the birds were travelling or why they should be found far away over the open sea in such a southerly latitude. Two swifts are perennially present and nest at Madeira, but the chimney-swallow is only known as a rare straggler; and in the last fifty-five years I have not known of the passing of any migrating flock, though our latitude is five hundred miles north of the locality indicated in the Bolama occurrence. So strange an incident might be taken from the pages of Pliny or Ambroise Paré, and cannot fail to interest those of your readers who are working on the subject of migration.

Madeira, October 27. Michael C. Grabham.

\section{Luminous Worms}

From the communications which reach me I learn that this subject is creating a great deal of interest. At the same time all the information is vague and unsatisfactory, and I an unable to obtain specimens of the creatures themselves. The vagueness of the information is due in great measure to the lack of knowledge which still prevails respecting the Oligo- 